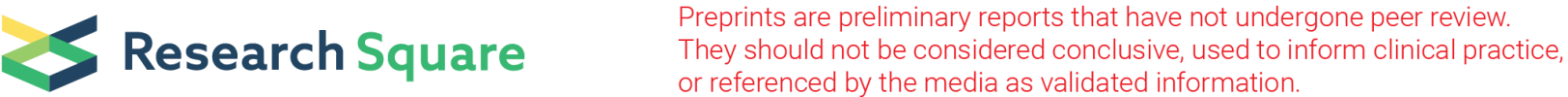

\section{An optimised Chromatin Immunoprecipitation (ChIP) method for starchy leaves of Nicotiana benthamiana to study histone modifications of an allotetraploid plant}

\section{Buddhini Ranawaka}

Queensland University of Technology

Milos Tanurdzic

University of Queensland

Peter Waterhouse

Queensland University of Technology

Fatima Naim ( $\sim$ fatima.naim@curtin.edu.au )

Curtin University https://orcid.org/0000-0001-8451-1104

\section{Methodology}

Keywords: Nicotiana benthamiana, Epigenetics, Histone modifications, ChIP-seq, Nuclei isolation, Chromatin shearing, H3K4me3, H3K9me2

Posted Date: May 8th, 2020

DOI: https://doi.org/10.21203/rs.3.rs-27075/v1

License: (c) (i) This work is licensed under a Creative Commons Attribution 4.0 International License. Read Full License

Version of Record: A version of this preprint was published at Molecular Biology Reports on November 25th, 2020. See the published version at https://doi.org/10.1007/s11033-020-06013-1. 


\section{Abstract \\ Background}

All flowering plants have evolved through multiple rounds of polyploidy throughout the evolutionary process. Intergenomic interactions between subgenomes in polyploid plants are predicted to induce chromatin modifications such as histone modifications to regulate expression of gene homoeologs. Nicotiana benthamiana is an ancient allotetraploid plant with ecotypes collected from climatically diverse regions of Australia. Studying the differences in chromatin landscape of this unique collection will shed light on the importance of chromatin modifications in gene regulation in polyploids as well its implications in adaptation of plants in environmentally diverse conditions. N.benthamiana is also an important biotechnological tool and it is widely used in virological research and functional genomics. Chromatin Immunoprecipitation and high throughput DNA sequencing (ChIP-seq) is well established technique used to study histone modifications. However, due to the starchy nature of mature N.benthamiana leaves, previously published protocols were unsuitable. The aim of this study was to optimise ChIP protocol for N.benthamiana leaves to facilitate comparison of chromatin modifications in two closely related ecotypes.

\section{Results}

Several steps of ChIP were optimised including tissue harvesting, nuclei isolation, nuclei storage, DNA shearing and DNA recovery. The higher amounts of starch in mature N.benthamiana leaves that coprecipitated with nuclei using previously published protocols, hindered chromatin shearing and resulted in low recovery of ChIP DNA. The optimised method reduced starch contamination and resulted in isolation of high quality nuclei suitable for next generation sequencing. Commonly available antibodies targeting histone 3 lysine 4 trimethylation (H3K4me3) and histone 3 lysine 9 dimethylation (H3K9me2) histone modifications were used and success of ChIP was confirmed by PCR and next generation sequencing.

\section{Conclusions}

An optimised ChIP method for mature leaves of N.benthamiana is described. It is relatively less laborious than previously published protocols and allows extraction of high quality nuclear genomic DNA from N.benthamiana. It is also the first comprehensive ChIP method for starchy leaves of N.benthamiana suitable for preparation of ChIP libraries for next generation sequencing.

\section{Background}

Nicotiana benthamiana is a plant species endemic to Australia first discovered by Benjamin Bynoe in 1839 (1). It is an important biotechnological tool and a model plant for economically important crop family Solanaceae, which includes potato, tomato, peppers and eggplant (2). The N.benthamiana ecotype 
used in laboratories all over the world is referred to as the 'Lab' isolate and another five wild isolates were collected from climaticaly diverse parts of Australia $(2,3)$. Following the polyploidisation processes, N.benthamiana may have successfully passed the initial stage of genome instability and entered the prolonged phase of genome evolution referred to as diploidisation. In this phase, duplicated genes, chromosomes or chromosome fragments are progressively lost or retained due to the combined modifications in genetic and epigenetic structures (4-6). Therefore, the species has an allotetraploid genome ( $3.1 \mathrm{~Gb}$ ) encoded in 19 chromosomes (aneutetraploid) $(7)$. It is considerably larger and more complex than the genome of the model plant Arabidopsis thaliana (8-11).

It is well established that histone modifications play a key role in regulation of biological processes (12) through their roles in the regulation of gene expression and genome integrity. Therefore, our understanding of the genetic control mechanisms involved in manipulation and expression of DNA is dependent on studies of the distribution of histone modifications in a genome (13). Histone modifications that lead to active transcription are categorised as euchromatic marks while modifications responsible for gene suppression are categorised as heterochromatic marks (14). In plants, some of these histone modifications mediate epigenetic regulation of gene expression underlying growth and development, including essential processes such as cell differentiation, floral transition, and gametogenesis (15).

The N-terminal tails of histones are exposed to a range of different post-translational modifications such as methylation, phosphorylation, acetylation, ubiquitylation and sumoylation (16). Some models have suggested that histone modifications can alter the interaction between histone-histone and histone-DNA through the action of protein complexes that recognise specific histone modifications and facilitate transcriptional activation or silencing $(17,18)$. Allis and colleagues $(19-21)$ proposed the 'histone code' hypothesis which refers to the sequential or combinatorial act of multiple histone modifications to regulate unique biological outcomes. This hypothesis describes three predictions, (i) different histone modifications could induce interactions with chromatin-associated proteins (ii) histone modifications on the same or different histone tails might be interactive and produce diverse combinations on any one nucleosome and (iii) the quality of higher order chromatin (euchromatin or heterochromatin) relies on the concentration and organisation of differentially modified nucleosomes. This 'nucleosome code' allows the assembly of different epigenetic states to allow diverse readouts of underlying genetic information such as gene activation or gene silencing (20). Histone code hypothesis was proven to be correct with the identification of enzymes that recognise combinatorial patterns of histone marks (22). The key proteins associated with these histone modifications are categorised as histone writers, readers and erasers. Histone writers are a group of enzymes capable of modifying specific amino acid residues on histone Nterminal tails where erasers remove these marks. Histone readers have specialised domains that can bind to specific histone marks and direct a particular transcriptional outcome (23-25).

In plants, genome-wide analysis of histone post-translational modifications showed that histone 3 lysine 4 trimethylation (H3K4me3), histone 3 lysine 36 dimethylation (H3K36me2) and histone 3 lysine 36 trimethylation ( $\mathrm{H} 3 \mathrm{~K} 36 \mathrm{me} 3)$ are enriched in highly expressed genes. These modifications were distributed 
throughout the gene with H3K4me3 enriched at the promoter and 5' end of the genes (26) and H3K36me2 and H3K36me3 enriched in the transcribed regions $(27,28)$. Another active mark is H3K4me2, a gene specific histone mark found at the 5 ' end and promoter of active genes $(29,30)$. However, the presence of H3K4me2 does not always correlate with active transcription (31-33). Histone 3 lysine 9 acetylation (H3K9ac) is a euchromatic mark directly associated with active gene transcription and elongation (34, 35). The heterochromatic mark, $\mathrm{H} 3 \mathrm{~K} 9 \mathrm{me2}$, is involved with transcriptional silencing of transposons and repetitive sequences, enriched over the promoter and gene body $(36,37)$. Another gene silencing mark is histone 3 lysine 27 trimethylation (H3K27me3) found in tissue specific and developmentally regulated genes and it is enriched along the gene body (35).

The genomic localisation of histone modifications in plant genomes can be determined through chromatin immunoprecipitation followed by high-throughput DNA sequencing (ChIP-seq). This method allows for genome-wide mapping of transcription factors, DNA binding proteins and histone modifications. ChIP protocols were initially developed for yeast (38), Drosophila (39) and then for mammalian cells (40). These reported protocols are not always directly applicable to plant tissues due to structural and biochemical differences between plant and animal cells (41). Plant cells have rigid cell walls, larger vacuoles, and higher levels of lignin and cellulose. Therefore, ChIP protocols have been heavily modified to extract high quality chromatin from plant tissues (42). Generally, in a ChIP-seq workflow, formaldehyde is used to crosslink DNA binding proteins to DNA (in the case of native ChIP, where no crosslinking is performed, this step can be omitted), followed by the fragmentation of chromatin to 200-1000 bp fragments, immunoprecipitation of soluble chromatin fragments with antibodies against a histone modification of interest, reverse crosslinking the immunoprecipitated complexes to release the DNA fragments and their preparation for next generation sequencing (NGS) (13, $41,43)$.

N.benthamiana plants are used for rapid transient gene expression and metabolic engineering by agroinfiltration as well as to study plant-pathogen interactions. The collection of wild N.benthamiana isolates provides a unique resource to study histone modifications with implications on manipulation of gene homoeologs, response to environmental stresses and synthetic biology. Although these isolates are $>90 \%$ genetically identical, there are many morphological changes implicating other forms of gene regulation and chromatin landscape being one of them. Therefore, in this study we aimed to develop a simple and reliable ChIP protocol for mature N.benthamiana leaves to determine the presence and distribution of gene regulatory histone modifications. The majority of published plant ChIP protocols are developed for seedlings and young plant tissues $(15,41,42,44-46)$ and the methods developed for Arabidopsis (44) and tomato leaves (46) were unsuitable for ChIP of mature N.benthamiana leaves. Here, we use a combination of nuclei isolation and chromatin immunoprecipitation protocols to enable studies of chromatin landscape of mature N.benthamiana leaves.

\section{Methods}

\section{Plant material}


N.benthamiana plants of Lab and QId ecotypes were grown on soil (Plugger custom Mix, supplemented with Osmocote ${ }^{\circledR}$ slow release fertiliser) under controlled environmental conditions of $25^{\circ} \mathrm{C}$ and a 16 hour photoperiod. N.benthamiana Lab is the commonly used ecotype and Qld refers to the ecotype collected from Queensland in Australia (3). Leaves of 5 weeks old plants were collected for crosslinking at the beginning of their photoperiod.

\section{Crosslinking Of DNA And Protein}

Two leaves $(\sim 3 \mathrm{~g})$ of 5 weeks of old N.benthamiana plants $(\sim 5.5 \times 5.0 \mathrm{~cm})$ were rinsed twice with $40 \mathrm{~mL}$ of water and patted dry using paper towel, transferred to Falcon tube containing $37 \mathrm{~mL}$ of $1 \%$ pre-chilled formaldehyde (Sigma-Aldrich, 252549), vacuum infiltrated for $10 \mathrm{~min}$ at $-25 \mathrm{in} \mathrm{Hg}$. The amount of tissue should not exceed one Falcon tube. Crosslinking was stopped by addition of $2.5 \mathrm{~mL}$ of $2 \mathrm{M}$ glycine to a final concentration of $0.125 \mathrm{M}$, solutions were mixed well, and vacuum infiltration continued for 5 min at $-25 \mathrm{in} \mathrm{Hg}$. It is critical that the leaf tissues remain in solution throughout the vacuum infiltration process. The buffers were removed, crosslinked materials were rinsed with milliQ water and any excess water was removed thoroughly using paper towels.

\section{Chromatin Isolation From Crosslinked Tissue}

All buffers were prepared except for the following steps carried out just before nuclei isolation. Sodium metabisulfite was added to NEB (nuclei extraction buffer containing $0.5 \mathrm{M}$ Mannitol, $10 \mathrm{mM}$ PIPES-KOH, $10 \mathrm{mM} \mathrm{MgCl}_{2}$, 2\% PVP40, $200 \mathrm{mM}$ L-lysine monohydrochloride, $6 \mathrm{mM} \mathrm{EGTA}$ ) to a final concentration of $10 \mathrm{mM}$. NEB complete buffer was prepared by the addition of $\beta$ - mercaptoethanol to half of NEB to a final concentration of $0.4 \mathrm{mM}$. $150 \mathrm{~mL}$ of ice-cold NEB complete buffer was poured into a Waring blender containing 4-5 g of crosslinked leaf tissue and homogenised for 30 seconds in low setting. The homogenate was filtered through 4 layers of cheesecloth into a $250 \mathrm{~mL}$ sterile glass beaker on ice followed by second filtration through 4 layers of miracloth into a $250 \mathrm{~mL}$ sterile glass measuring cylinder. The volume was adjusted to $147 \mathrm{~mL}$ with NEB complete buffer followed by addition of $3 \mathrm{~mL}$ of $25 \%$ Triton X-100 (prepared with NEB complete buffer), cylinder sealed with parafilm and mixed very gently by inversion 10-20 times. Homogenate was aliquoted into three $50 \mathrm{~mL}$ Falcon tubes and spun down at $57 \mathrm{~g}$ at $4{ }^{\circ} \mathrm{C}$ for $2 \mathrm{~min}$. The pellet was discarded, and supernatant was transferred to a new set of tubes and spun down at $1800 \mathrm{~g}$ for $15 \mathrm{~min}$ at $4^{\circ} \mathrm{C}$. After centrifugation supernatant was discarded and each pellet was resuspended in $50 \mathrm{~mL}$ NEB. Contents were mixed gently by inversion until the pellet was completely resuspended and spun down again at $1800 \mathrm{~g}$ for $15 \mathrm{~min}$ at $4^{\circ} \mathrm{C}$. The supernatant was discarded, pellet resuspended in $5 \mathrm{~mL}$ of NEB and all resuspended nuclei pellets were combined into one Falcon tube to a final volume of $50 \mathrm{~mL}$ with NEB. Tubes were spun down again as before, supernatant was discarded and the nuclei fraction was resuspended in $1.5 \mathrm{~mL}$ of nuclei storage buffer $(20 \%$ Glycerol, $20 \mathrm{mM} \mathrm{HEPES}-\mathrm{KOH}$ (pH 7.2), $5 \mathrm{mM} \mathrm{MgCl}_{2}$ and $1 \mathrm{mM} \mathrm{DTT}$ ). The nuclei can either be stored at $-80{ }^{\circ} \mathrm{C}$ for later use or proceed with nuclei lysis and DNA shearing. 


\section{Nuclei Lysis And Chromatin Shearing}

An aliquot of nuclei resuspension (750 uL) was transferred into microcentrifuge tubes and centrifuged at $1000 \mathrm{rpm}$ for $10 \mathrm{~min}$. The supernatant was discarded, and the pellet was resuspended in $300 \mathrm{uL}$ of freshly prepared nuclei lysis buffer (50 mM Tris-HCl, pH 8, 10 mM EDTA, 1\% SDS, 50 mM Protease Inhibitor (Roche cOmplete Tablets, Mini EDTA-free, EASYpack 04693159001). A 5 uL aliquot from each sample was set aside for verifying the efficiency of chromatin shearing.

To compare shearing techniques, $100 \mathrm{uL}$ of sample was sheared with Diagenode Bioruptor ${ }^{\circledR}$ and $130 \mathrm{uL}$ of sample transferred into microtubes (520045-microTUBE Snap-Cap, AFA Fibre) for shearing with Covaris M220 ${ }^{\mathrm{TM}}$ Focused-ultrasonicator with SonoLab ${ }^{\mathrm{TM}}$ 7.2. The power was set to "High" in Diagenode Bioruptor ${ }^{\circledR}$ and a time course of shearing cycles $(14,16,18,20$ and 22 cycles) ( 30 seconds "ON", 30 seconds "OFF") was conducted. Chromatin shearing using Covaris sonicator was carried out using the "150 bp DNA $130 \mathrm{uL}$ microTUBE" program selected with Min Temp of - $18^{\circ} \mathrm{C}$, Set Point temperature of $20^{\circ} \mathrm{C}$ and Max Temp $-22^{\circ} \mathrm{C}$, treatment was at Peak power -50.0 , Duty factor -20.0 and Cycles/Burst - 200. Shearing was completed in 5 min and 32 seconds per sample.

The sonication efficiency was assessed using $5 \mathrm{uL}$ of sheared chromatin with $5 \mathrm{uL}$ unsheared DNA. DNA samples were treated with RNase A ( $1 \mathrm{uL}$ of $10 \mathrm{mg} / \mathrm{mL}$ RNase A, ThermoFisher Scientific, EN0531), $2 \mathrm{uL}$ of NEB restriction enzyme buffer 2 (NEBuffer 2, B7002S), 8 uL of deionised water and incubated at $37^{\circ} \mathrm{C}$ for $30 \mathrm{~min}$ followed by the addition of $2 \mathrm{uL}$ of $20 \mathrm{mg} / \mathrm{mL}$ Proteinase K (Promega V3021), $1 \mathrm{uL}$ of $1 \mathrm{M}$ Tris-HCL (pH 6.5), and incubation at $45^{\circ} \mathrm{C}$ for $15 \mathrm{~min}$. Samples were electrophoresed on $1.2 \%$ agarose gel in $1 \mathrm{X}$ TAE buffer at $100 \mathrm{~V}$ for $45 \mathrm{~min}$ (Fig. 2A, 2B).

The samples used for ChIP were sheared using Covaris sonicator due to reproducibility of shearing (Fig. 2B).

\section{Chromatin Immunoprecipitation}

Sonicated chromatin was centrifuged at $12000 \mathrm{rpm}$ at $4{ }^{\circ} \mathrm{C}$ for $5 \mathrm{~min}$ and the supernatant was transferred to a new tube. An aliquot of each sample $(20 \mathrm{uL})$ was set aside to serve as the 'input' DNA control. Volumes of chromatin samples were measured and adjusted to $1.5 \mathrm{~mL}$ by adding freshly prepared ChIP dilution buffer (1.1\% Triton X-100, 1.2 mM EDTA, $16.7 \mathrm{mM}$ Tris-HCl (pH 8), $167 \mathrm{mM} \mathrm{NaCl})$. Chromatin solutions were split into three tubes (500 uL each) that corresponded to the number of antibodies tested (Commercially available rabbit polyclonal antibodies against histone H3K4me3 (Abcam ab8580) and H3K9me2 (Diagenode C15410060)) and the 'no antibody control' (NAB). For six treatments (including two replicates per antibody, input and NAB samples) $60 \mathrm{uL}$ of magnetic beads (Dynabeads ${ }^{\mathrm{TM}}$ Protein A 10002D) were washed twice with $100 \mathrm{uL}$ of ChIP dilution buffer, resuspended in $60 \mathrm{uL}$ of ChIP dilution buffer and $10 \mathrm{uL}$ was transferred to each chromatin sample referred to as immunoprecipitation (IP) sample. Tubes were rotated in a tube rotator at $4^{\circ} \mathrm{C}$ for 1 hour. Meanwhile, $120 \mathrm{uL}$ aliquot of magnetic beads was washed twice with $150 \mathrm{uL}$ of phosphate buffer $\left(0.1 \mathrm{M} \mathrm{Na}_{2} \mathrm{HPO}_{4}, 5 \mathrm{mM} \mathrm{NaH}_{2} \mathrm{PO}_{4}, \mathrm{pH}\right.$ 
8.1), resuspended in $120 \mathrm{uL}$ of the same buffer and $20 \mathrm{uL}$ added to each ChIP sample. A $5 \mathrm{uL}$ aliquot of the appropriate antibody was added to each ChIP samples (water for the NAB samples) and tubes were rotated in a tube rotator at $4{ }^{\circ} \mathrm{C}$ for 1 hour. Beads were captured in precleared chromatin and the supernatant was transferred into corresponding tubes containing antibody-bead complex. Contents were mixed by pipetting and rotated overnight at $4{ }^{\circ} \mathrm{C}$. Beads were recovered using a magnetic stand and the supernatant was removed. Beads were washed three times sequentially (Table 1) with Low salt wash buffer (150 mM NaCl, 0.1\% SDS, 1\% Triton X-100, 2 mM EDTA, 20 mM Tris-HCl (pH 8)), High salt wash buffer (500 mM NaCl, 0.1\% SDS, 1\% Triton X-100, 2 mM EDTA, 20 mM Tris-HCl (pH 8)), LiCl wash buffer (0.25 mM LiCl, 1\% IGEPAL, 1\% Sodium deoxycholate, $1 \mathrm{mM}$ Tris-HCl (pH 8)) and TE buffer (100 mM Tris$\mathrm{HCl}(\mathrm{pH} 8), 10 \mathrm{mM}$ EDTA).

Immunoprecipitated complex was eluted in 175 uL of TES buffer (100 mM Tris- $\mathrm{HCl}$ (pH 8), $10 \mathrm{mM}$ EDTA, $1 \%$ SDS) followed by brief vortexing and incubation at $65^{\circ} \mathrm{C}$ for $15 \mathrm{~min}$ with gentle agitation. The beads were captured using magnetic stand and supernatant was carefully transferred to a new tube. This step was repeated with a second elution in $175 \mathrm{uL}$ of TES and the two elutes of each sample were combined. At this stage $350 \mathrm{uL}$ of TES was added to 'input' DNA samples.

Table 1

Washing procedure of recovered magnetic beads

First Wash

(i) Resuspend beads in $800 \mathrm{uL}$ buffer

(ii) Remove supernatant using a magnetic stand
Second Wash

(i) Resuspend beads in $800 \mathrm{uL}$ buffer

(ii) Wash beads for 5 minutes with rotation

(iii) Remove the supernatant using a

magnetic stand

\section{Reverse Crosslinking, DNA Recovery And ChIP Validation}

To reverse crosslink, $20 \mathrm{uL}$ of $5 \mathrm{M} \mathrm{NaCl}$ was added to each sample including 'input' DNA control samples and incubated overnight at $65^{\circ} \mathrm{C}$. All samples were treated with $2 \mathrm{uL}$ of $10 \mathrm{mg} / \mathrm{mL}$ RNase $A$ (ThermoFisher Scientific EN0531), and incubated at $37^{\circ} \mathrm{C}$ for $30 \mathrm{~min}$ followed by the addition of $1 \mathrm{uL}$ of $20 \mathrm{mg} / \mathrm{mL}$ Proteinase K (Promega V3021), $10 \mathrm{uL}$ of 0.5 M EDTA, $20 \mathrm{uL}$ of $1 \mathrm{M}$ Tris-HCl (pH 6.5) and incubation at $45^{\circ} \mathrm{C}$ for 1 hour. Samples were cleaned using phenol:chloroform (1:1, vol/vol). One volume of phenol:chloroform $(1: 1, \mathrm{vol} / \mathrm{vol})$ was added to each sample, mixed thoroughly and centrifuged at room temperature for $5 \mathrm{~min}$ at $14000 \mathrm{rpm}$. The upper aqueous layer was transferred to a clean tube followed by addition of $0.1 \mathrm{X}$ total sample volume of $3 \mathrm{M} \mathrm{NaOAc}$ and $2.5 \mathrm{X}$ supernatant volume of $100 \%$ ethanol and DNA precipitated overnight at $-20^{\circ} \mathrm{C}$. Samples were centrifuged for $30 \mathrm{~min}$ at $14000 \mathrm{rpm}$ at $4{ }^{\circ} \mathrm{C}$, supernatant discarded and $500 \mathrm{uL}$ of $70 \%$ ethanol added to each tube followed by centrifugation at $14000 \mathrm{rpm}$ for $5 \mathrm{~min}$ at $4{ }^{\circ} \mathrm{C}$. Supernatant was carefully removed, DNA pellet air dried and resuspended in 
20 uL of nuclease free water. A second column clean-up was carried out using MinElute ${ }^{\circledR}$ Reaction Cleanup kit (QIAGEN 28204) as per manufacturer's instructions and DNA eluted in 15 uL of elution buffer.

For ChIP DNA validation, 1 uL of input DNA and ChIP DNA were diluted in 50 uL and 10 uL of TE buffer, respectively. Primer pairs were designed using the latest assembly of N.benthamiana genome (www.nbenth.com) to specifically amplify a $\sim 200$ bp fragment of Ef-1a (active gene to probe success of ChIP with H3K4me3 (47), gene ID Nbv6.1trA73553) and Ty1-copia (retrotransposon to probe success of ChIP with H3K9me2 (48), gene ID Nbv6.1trA2043) (Table 2). PCR was set up using 1.5 uL of the diluted extract as template in $2 \times 2 \mathrm{G}$ Robust HotStart ReadyMix (KAPA Biosystems KK5704). The PCR cycle conditions were as follows: an initial denaturation step at $95^{\circ} \mathrm{C}$ for $3 \mathrm{~min}, 30$ cycles of $95^{\circ} \mathrm{C}$ for $15 \mathrm{sec}$, $60{ }^{\circ} \mathrm{C}$ for $15 \mathrm{sec}$, and $72{ }^{\circ} \mathrm{C}$ for $30 \mathrm{sec}$, and a final extension step at $72{ }^{\circ} \mathrm{C}$ for $2 \mathrm{~min}$. The resulting PCR products were electrophoresed on a 1\% TAE agarose gel (Fig. 3).

Table 2

Primer sequences used to validate ChIP DNA

\begin{tabular}{|lll|}
\hline Locus & Forward primer sequence & Reverse primer sequence \\
\hline EF-1a & CCACGTCGACTCTGGTAAGT & AGCACCCAGGCATACTTGAA \\
\hline Ty1-copia & AGGACATGTGAAGAAGCCGA & TTGTTAGCCACCATGTTCGC \\
\hline
\end{tabular}

\section{ChIP-seq Library Preparation}

ChIP DNA concentrations were determined using Qubit®2.0 Fluorometer followed by library preparation using NEBNext® Ultra ${ }^{\text {TM }}$ II DNA Library Prep Kit for Illumina (E7645S) as per manufacturer's specifications.

Libraries were prepared with $2 \mathrm{ng}$ of ChIP DNA and quantified using Qubit®2.0 Fluorometer and qPCR methods as per Library Quantification Kit Illumina ${ }^{\circledR}$ Platforms (KAPA Biosystems) (Table 3). The final concentration of libraries ranged between $17-63 \mathrm{ng} / \mathrm{uL}$ and an aliquot of each library was electrophoresed on a 1.5\% agarose gel. The size of the fragments ranged between 200-500 bp (Fig. 4A), which was further confirmed by LabChip GX (Caliper Life Sciences) (Fig. 4B). Libraries were sequenced at the Central Analytical Research Facility (CARF), Queensland University of Technology, using Illumina NextSeq ${ }^{\circledR} 500$ with output of 75 bp paired-end reads (TG NextSeq ${ }^{\circledR} 500 / 550$ High Output Kit v2, 75 cycle, TG-160-2005). 
Table 3

Library concentrations for ChIP and Input DNA samples

\begin{tabular}{|llll|}
\hline Ecotype & Sample & Antibodies & Library Concentration (ng/uL) \\
\hline Lab & Rep 1 & Input & 37.30 \\
& Rep 2 & Input & 33.00 \\
& Rep 1 & H3K4me3 & 63.60 \\
& Rep 2 & H3K4me3 & 17.10 \\
\hline & Rep 1 & H3K9me2 & 22.24 \\
\hline Rep 2 & H3K9me2 & 31.60 \\
\hline Rep 1 & Input & 21.20 \\
\hline Rep 2 & Input & 40.20 \\
\hline Rep 1 & H3K4me3 & 48.40 \\
\hline Rep 2 & H3K4me3 & 38.40 \\
\hline Rep 1 & H3K9me2 & 20.80 \\
\hline Rep 2 & H3K9me2 & 17.40 \\
\hline
\end{tabular}

\section{Results}

\section{Formaldehyde vacuum infiltration}

Freshly prepared $1 \%$ formaldehyde is used for crosslinking and this was found to be appropriate for mature leaves of N.benthamiana (Fig. 1A, 1B). The success of formaldehyde vacuum infiltration was determined by the obvious physical changes in leaf samples. Before crosslinking, leaf samples floated on the surface of $1 \%$ formaldehyde solution, and the abaxial and adaxial surfaces of the leaf tissues differed in colour (Fig. 1C). After crosslinking, tissues sunk to the bottom of the tube and looked translucent and water-soaked (Fig. 1D) indicating the success of crosslinking.

\section{Removal Of Starch Contamination In Nuclei Extract}

The next step of a conventional ChIP-seq workflow requires chromatin extraction from the crosslinked material. With conventional methods $(44,49)$ we noticed that a large amount of starch co-precipitated with chromatin (Fig. 1E). This reduced the final quality and quantity of precipitated DNA and samples were contaminated with starch, proteins and plastid DNA (Fig. 1E and 1G). In comparison, the modified protocol described here yielded high quality nuclei (Fig. 1F) which resulted in high quality chromatin preparation (Fig. 1G). The described method is a combination of N.benthamiana nuclei isolation methods 
$(49,50)$ and ChIP methods developed for Arabidopsis and tomato $(41,44,46)$. To further eliminate starch contamination, leaves were harvested at the beginning of their photoperiod.

\section{Successful Shearing Of Chromatin}

The next crucial step in ChIP protocol is chromatin shearing and generally a Bioruptor ${ }^{\circledR}$ sonicator is used. We tested different number of sonication cycles $(14,16,18,20,22)$ to determine the optimum number of cycles to achieve the required sheared DNA fragment range (200-500 bp). This was achieved with 22 cycles and the lower number of sonication cycles resulted in incomplete shearing and larger fragment sizes (Fig. 2A). We then compared this to shearing efficiency of Covaris M220 ultrasonicator which produced the desired chromatin shearing results with narrow fragment range and no requirement for optimisation (Fig. 2A and 2B). The efficiency of shearing was confirmed by electrophoresing an aliquot of each sample on an agarose gel. With a clear difference obvious between the sheared and input samples using both techniques (Fig. 2A). The fragmentation was consistent between the biological replicates used for Lab and Qld samples (Fig. 2B).

\section{Chromatin Immunoprecipitation And Validation}

The success of chromatin immunoprecipitation is confirmed by PCR which were carried out for N.benthamiana ChIP samples using primer pairs specific to elongation factor 1 alpha (EF-1a) and Ty1copia retrotransposon (Fig. 3). The histone modification statuses of EF-1a gene and Ty1-copia retrotransposon are expected to be enriched in $\mathrm{H} 3 \mathrm{~K} 4 \mathrm{me} 3$ and $\mathrm{H} 3 \mathrm{~K} 9 \mathrm{me} 2$ marks, respectively $(47,48)$. The IPs were validated for active and inactive genes. A slight non-specific amplification was also observed, and this may have been due to the allotetraploid genome of N.benthamiana with large gene families and partially resolved gene activity of homoeologs. Most genes have two homoeologs and in some instances one copy is active and the other copy is aberrant or inactive (2). For such gene homoeologs and specially for EF-1a, a gene with at least 16 copies in N.benthamiana, it is possible to see weak amplification in H3K9me2. Willing and colleagues (51) have shown that copia elements are enriched in H3K4me3 ChIP which explains the slight amplification of Ty1-copia in H3K4me3 ChIP.

\section{ChIP-seq Library Preparation And Data Analysis}

The concentration of DNA in ChIP samples was quantified using Qubit ${ }^{\circledR}$ prior to library preparation (Table 4). As expected, the input control samples had a higher concentration compared to the ChIP samples. The concentration of DNA in ChIP samples enriched for H3K4me3 and H3K9me2 marks were between 2-4 ng/uL which was sufficient for library preparation. Libraries were successfully prepared and Illumina NextSeq ${ }^{\circledR} 500$ platform was used for sequencing. 
Table 4

Concentrations of N.benthamiana ChIP DNA recovered after antibody conjugation

\begin{tabular}{|llll|}
\hline Ecotype & Sample & Antibodies & Antibody conjugated/ Input DNA (ng/uL) \\
\hline Lab & Rep 1 & Input & 14.22 \\
& Rep 2 & Input & 14.46 \\
& Rep 1 & H3K4me3 & 2.56 \\
& Rep 2 & H3K4me3 & 2.96 \\
& Rep 1 & H3K9me2 & 3.24 \\
& Rep 2 & H3K9me2 & 3.92 \\
Qld & Rep 1 & Input & 14.30 \\
& Rep 2 & Input & 15.24 \\
Rep 1 & H3K4me3 & 2.06 \\
Rep 2 & H3K4me3 & 2.74 \\
Rep 1 & H3K9me2 & 3.08 \\
\hline Rep 2 & H3K9me2 & 3.10 \\
\hline
\end{tabular}

Quality control checks of raw reads were carried out using FastQC (Table 5) (52) and poor quality reads were removed using Trimmomatic (53). After read alignment using Bowtie2 to latest assembly of N.benthamiana genome (www.nbenth.com) (54), DeepTools (55) was used to normalise ChIP reads against control input reads and the results (files generated by bamCompare tool) were visualised on Integrative Genomics Viewer (IGV) (56) (Fig. 5). The differential distribution of H3K4me3 and H3K9me2 can be clearly observed over two selected transcriptionally active (Fig. 5A) and repressed (Fig. 5B) genes in N.benthamiana genome. The comparisons showed that H3K4me3 is highly enriched over the transcriptionally active genes while $\mathrm{H} 3 \mathrm{~K} 9 \mathrm{me} 2$ is enriched over transcriptionally repressed genes, and transposable elements and repeats, proving the success and accuracy of the modified method. RNA sequencing reads (available from Waterhouse laboratory) from mature leaves of N.benthamiana are also overlayed with the ChIP peaks to further confirm ChIP-seq data. 
Table 5

Basic sequencing quality control parameters of ChIP-seq libraries

\begin{tabular}{|llllllll|}
\hline Ecotype & Sample & Antibody & $\begin{array}{l}\text { Total } \\
\text { Reads } \\
\text { (millions) }\end{array}$ & $\begin{array}{l}\text { Sequences } \\
\text { flagged as poor } \\
\text { quality }\end{array}$ & $\begin{array}{l}\text { GC } \\
\text { GC }\end{array}$ & $\begin{array}{l}\text { \%overrepr- } \\
\text { esented } \\
\text { sequences }\end{array}$ & $\begin{array}{l}\text { Adapter } \\
\text { content }\end{array}$ \\
\hline Lab & Rep 1 & Input & 258 & 0 & 37 & 0.11 & 0 \\
\hline & Rep 2 & Input & 248 & 0 & 37 & 0.00 & 0 \\
\hline & Rep 1 & H3K4me3 & 252 & 0 & 43 & 0.10 & 0 \\
\hline Rep 2 & H3K4me3 & 204 & 0 & 40 & 0.10 & 0 \\
\hline Rep 1 & H3K9me2 & 295 & 0 & 40 & 0.20 & 0 \\
\hline Rep 2 & H3K9me2 & 268 & 0 & 40 & 0.10 & 0 \\
\hline Rep 1 & Input & 225 & 0 & 38 & 0.11 & 0 \\
\hline Rep 2 & Input & 257 & 0 & 38 & 0.20 & 0 \\
\hline Rep 1 & H3K4me3 & 146 & 0 & 42 & 0.11 & 0 \\
\hline Rep 2 & H3K4me3 & 258 & 0 & 43 & 0.11 & 0 \\
\hline Rep 1 & H3K9me2 & 225 & 0 & 41 & 0.11 & 0 \\
\hline Rep 2 & H3K9me2 & 280 & 0 & 39 & 0.00 & 0 \\
\hline
\end{tabular}

\section{Discussion}

To enable studies of histone modifications in polyploid, N.benthamiana, we combined nuclei isolation $(49,50)$ and ChIP methods $(41,44,46)$. Various steps including tissue harvesting, nuclei isolation, nuclei storage, chromatin shearing and ChIP DNA recovery were optimised to yield high quality ChIP DNA suitable for next generation sequencing. Generally, 5-6 weeks old N.benthamiana Lab isolate plants are used for genetic manipulation to study plant-microbe interactions, metabolic pathways, vaccine production and synthetic biology $(2,3,57-60)$. A comparative analysis of $N$.benthamiana ecotypes collected from climatically harsh and diverse locations of Australia are also suitable for studying biotic and abiotic stress due to their adaptation (2). Therefore, we sought to develop a ChIP-seq protocol for mature leaves of 5 weeks old N.benthamiana plants.

The first critical step in plant ChIP method is crosslinking (61). The leaf tissues were fixated in formaldehyde due to its cell permeability, rapid reactivity and reversibility over other crosslinking agents $(62,63)$. Freshly diluted formaldehyde solution was used for crosslinking $(64)$ to avoid oxidation products of formaldehyde such as formic acid and paraformaldehyde. Furthermore, to enable successful reversal of crosslinking, it is crucial to use $1 \%$ formaldehyde and to not exceed the duration of vacuum infiltration. An appropriate amount of leaf tissue was used for complete submergence in the formaldehyde solution throughout the duration of vacuum infiltration (42). The process of vacuum infiltration replaces the air 
inside mesophyll cells of the leaf tissues with aqueous formaldehyde (46). Therefore, completion of fixation is assessed by the translucent and water-soaked appearance of tissue.

Traditionally, plant ChIP protocols are laborious and time consuming due to buffer preparation, chromatin isolation and DNA shearing $(46,65)$. In this method, only a single nuclei extraction buffer (NEB) was necessary for successful isolation of nuclei. To enable storage of nuclei prep for future use and suitable for other sequencing techniques (such as ATAC and bisulfite sequencing), an extra step was added by resuspending nuclei in nuclei storage buffer and storage at $-80^{\circ} \mathrm{C}$ (Fig. 6). DNA fragmentation was also optimised by using the versatile Covaris ultrasonicator which takes 5 min and 32 seconds to shear DNA in contrast to previous report of $N$.benthamiana leaf ChIP requiring 60 min sonication with Bioruptor ${ }^{\circledR}$ sonicator (65). The sonication step with Bioruptor ${ }^{\circledR}$ sonicator also initially requires fragmentation monitoring by gel electrophoresis to empirically identify the optimum number of sonication cycles $(43,67$, 68). Covaris ultrasonicator is more efficient, reproducible and we obtained a uniform range of fragmented DNA for the two ecotypes of N.benthamiana.

Another critical step to enable high quality ChIP-seq library preparation is to eliminate buffer salts and phenol. Traditionally, DNA is extracted once with phenol/chloroform (1:1, vol/vol) and recovered by precipitation with ethanol after reversal of crosslinking. This technique is appropriate for PCR based analysis however not ideal for next generation sequencing. Therefore, our optimised protocol uses phenol/chloroform (1:1, vol/vol) followed by a second clean up with QIAGEN affinity column. The affinity column is suitable for clean-up of DNA fragments ranging between $70 \mathrm{bp}$ and $4 \mathrm{~kb}$.

We further confirmed the success of the protocol by analysing the H3K4me3 and H3K9me2 ChIP-seq results (Fig. 5). An overlay of histone modification peaks and RNA sequencing reads using representative genes from N.benthamiana genome confirm the success of the protocol. Furthermore, the global genomic comparison of the sequenced libraries for H3K4me3 and H3K9me2 for the two N.benthamiana ecotypes are being analysed to understand the implications of chromatin landscape on the phenotypic and environmental adaptation of the species.

\section{Conclusion}

The protocol described here allows for extraction of high-quality chromatin from mature leaves of N.benthamiana by reducing starch contamination. There are many advantages of the described method including simplicity, reduced preparation time and high quality and yield of ChIP samples suitable for next generation sequencing. The protocol will be useful in epigenetic research using the increasingly popular model plant, N.benthamiana and tissues of other plant species that have high starch content such as tobacco, potato and apple. This technique will enable important studies of wild N.benthamiana ecotypes and the implication of chromatin landscape in adaptation of plants in climatically diverse regions.

\section{Declarations}




\section{Ethics approval and consent to participate}

Not applicable

\section{Consent for publication}

Not applicable

\section{Availability of data and materials}

The datasets analysed during the current study are available from the corresponding author on request.

\section{Competing interests}

The authors declare that they have no competing interests.

\section{Funding}

This work was funded by Australian Research Council (ARC), grant number FL160100155.

\section{Authors' contributions}

FN and PMW designed the study, BR performed the experiments, BR and FN wrote the first draft of manuscript and all authors contributed to data analysis and improvement of manuscript.

\section{Acknowledgements}

The authors thank Drs Kevin Dudley, Victoria Coyne and Elena Hilario for providing expert technical advice, Dr Michal Lorenc for assisting in bioinformatic analysis and Mr Zacharie LeBlanc for help with vacuum infiltration set up.

\section{References}

1. Goodin MM, Zaitlin D, Naidu RA, Lommel SA. Nicotiana benthamiana: its history and future as a model for plant-pathogen interactions. Molecular plant-microbe interactions. 2008;21(8):1015-26.

2. Bally J, Jung H, Mortimer C, Naim F, Philips JG, Hellens R, et al. The rise and rise of Nicotiana benthamiana: A plant for all reasons. Annual Review of Phytopathology. 2018;56(1):405-26.

3. Bally J, Nakasugi K, Jia F, Jung H, Ho SY, Wong M, et al. The extremophile Nicotiana benthamiana has traded viral defence for early vigour. Nature Plants. 2015;1(11):15165.

4. De Storme N, Mason A. Plant speciation through chromosome instability and ploidy change: cellular mechanisms, molecular factors and evolutionary relevance. Current Plant Biology. 2014;1:10-33.

5. Chang PL, Dilkes BP, McMahon M, Comai L, Nuzhdin SV. Homoeolog-specific retention and use in allotetraploid Arabidopsis suecica depends on parent of origin and network partners. Genome Biol. 2010;11(12):R125. 
6. Gallagher JP, Grover CE, Hu G, Wendel JF. Insights into the ecology and evolution of polyploid plants through network analysis. Mol Ecol. 2016;25(11):2644-60.

7. Burbidge NT. The Australian species of Nicotiana L. (Solanaceae). Aust J Bot. 1960;8(3):342-80.

8. Bennett MD, Leitch IJ. Nuclear DNA amounts in angiosperms. Ann Bot. 1995;76(2):113-76.

9. Narayan RKJ. Nuclear DNA changes, genome differentiation and evolution in Nicotiana (Solanaceae). Plant Syst Evol. 1987;157(3):161-80.

10. Bennett MD, Leitch IJ. Nuclear DNA amounts in angiosperms: progress, problems and prospects. Ann Bot. 2005;95(1):45-90.

11. Bennett MD, Leitch IJ, Price HJ, Johnston JS. Comparisons with Caenorhabditis ( $100 \mathrm{Mb})$ and Drosophila $(\sim 175 \mathrm{Mb})$ using flow cytometry show genome size in Arabidopsis to be $\sim 157 \mathrm{Mb}$ and thus approximately $25 \%$ larger than the Arabidopsis genome initiative estimate of $\sim 125 \mathrm{Mb}$. Ann Bot. 2003;91(5):547-57.

12. Bannister AJ, Kouzarides T. Regulation of chromatin by histone modifications. Cell Res. 2011;21(3):381.

13. Park PJ. ChIP-seq: advantages and challenges of a maturing technology. Nat Rev Genet. 2009;10(10):669.

14. Ha M, Ng DW, Li W-H, Chen ZJ. Coordinated histone modifications are associated with gene expression variation within and between species. Genome Res. 2011;21(4):590-8.

15. You Q, Yi X, Zhang K, Wang C, Ma X, Zhang X, et al. Genome-wide comparative analysis of H3K4me3 profiles between diploid and allotetraploid cotton to refine genome annotation. Sci Rep. 2017;7(1):9098.

16. Kim JJ, Lee SY, Miller KM. Preserving genome integrity and function: the DNA damage response and histone modifications. Crit Rev Biochem Mol Biol. 2019;54(3):208-41.

17. Li X-M, Li XD. Interrogating interactions and modifications of histones in live cells. Cell Chemical Biology. 2018;25(1):1-3.

18. Lawrence M, Daujat S, Schneider R. Lateral thinking: how histone modifications regulate gene expression. Trends Genet. 2016;32(1):42-56.

19. Strahl BD, Allis CD. The language of covalent histone modifications. Nature. 2000;403(6765):41-5.

20. Jenuwein T, Allis CD. Translating the histone code. Science. 2001;293(5532):1074.

21. Chi P, Allis CD, Wang GG. Covalent histone modifications-miswritten, misinterpreted and mis-erased in human cancers. Nat Rev Cancer. 2010;10(7):457-69.

22. Janssen KA, Sidoli S, Garcia BA. Recent achievements in characterizing the histone code and approaches to integrating epigenomics and systems biology. Methods Enzymol. 2017;586:359-78.

23. Biswas $\mathrm{S}$, Rao CM. Epigenetic tools (the writers, the readers and the erasers) and their implications in cancer therapy. Eur J Pharmacol. 2018;837:8-24.

24. Pfannenstiel BT, Greco C, Sukowaty AT, Keller NP. The epigenetic reader SntB regulates secondary metabolism, development and global histone modifications in Aspergillus flavus. Fungal Genet Biol. 
2018;120:9-18.

25. Gillette TG, Hill JA. Readers, writers, and erasers: chromatin as the whiteboard of heart disease. Circ Res. 2015;116(7):1245-53.

26. Zeng Z, Zhang W, Marand AP, Zhu B, Buell CR, Jiang J. Cold stress induces enhanced chromatin accessibility and bivalent histone modifications H3K4me3 and H3K27me3 of active genes in potato. Genome Biol. 2019;20(1):123.

27. Zhang X, Bernatavichute YV, Cokus S, Pellegrini M, Jacobsen SE. Genome-wide analysis of mono-, diand trimethylation of histone H3 lysine 4 in Arabidopsis thaliana. Genome Biol. 2009;10(6):R62.

28. Mahrez W, Arellano MST, Moreno-Romero J, Nakamura M, Shu H, Nanni P, et al. H3K36ac is an evolutionary conserved plant histone modification that marks active genes. Plant Physiol. 2016;170(3):1566-77.

29. Cheng K, Xu Y, Yang C, Ouellette L, Niu L, Zhou X, et al. Histone tales: lysine methylation, a protagonist in Arabidopsis development. J Exp Bot. 2020;71(3):793-807.

30. Du Z, Li H, Wei Q, Zhao X, Wang C, Zhu Q, et al. Genome-wide analysis of histone modifications: H3K4me2, H3K4me3, H3K9ac, and H3K27ac in Oryza sativa L. Japonica. Mol Plant. 2013;6(5):1463-72.

31. Schubert D, Clarenz O, Goodrich J. Epigenetic control of plant development by Polycomb-group proteins. Curr Opin Plant Biol. 2005;8(5):553-61.

32. Lauria M, Rossi V. Epigenetic control of gene regulation in plants. Biochimica et Biophysica Acta (BBA) -. Gene Regulatory Mechanisms. 2011;1809(8):369-78.

33. Liu Y, Liu K, Yin L, Yu Y, Qi J, Shen W-H, et al. H3K4me2 functions as a repressive epigenetic mark in plants. Epigenetics Chromatin. 2019;12(1):40.

34. Gates LA, Shi J, Rohira AD, Feng Q, Zhu B, Bedford MT, et al. Acetylation on histone H3 lysine 9 mediates a switch from transcription initiation to elongation. J Biol Chem. 2017;292(35):14456-72.

35. Wang X, Elling AA, Li X, Li N, Peng Z, He G, et al. Genome-wide and organ-specific landscapes of epigenetic modifications and their relationships to mRNA and small RNA transcriptomes in Maize. Plant Cell. 2009;21(4):1053.

36. Zhou J, Wang X, He K, Charron J-BF, Elling AA, Deng XW. Genome-wide profiling of histone H3 lysine 9 acetylation and dimethylation in Arabidopsis reveals correlation between multiple histone marks and gene expression. Plant Mol Biol. 2010;72(6):585-95.

37. Zhang C, Du X, Tang K, Yang Z, Pan L, Zhu P, et al. Arabidopsis AGDP1 links H3K9me2 to DNA methylation in heterochromatin. Nat Commun. 2018;9(1):4547.

38. Ezhkova E, Tansey WP. Chromatin immunoprecipitation to study protein-DNA interactions in budding yeast. Yeast Protocol: Springer; 2006. pp. 225-44.

39. Sandmann T, Jakobsen JS, Furlong EE. ChIP-on-chip protocol for genome-wide analysis of transcription factor binding in Drosophila melanogaster embryos. Nat Protoc. 2006;1(6):2839. 
40. Chaya D, Zaret KS. Sequential chromatin immunoprecipitation from animal tissues. Methods in Enzymology. 376: Elsevier; 2003. p. $361-72$.

41. Saleh A, Alvarez-Venegas R, Avramova Z. An efficient chromatin immunoprecipitation (ChIP) protocol for studying histone modifications in Arabidopsis plants. Nat Protoc. 2008;3(6):1018.

42. Yamaguchi N, Winter CM, Wu M-F, Kwon CS, William DA, Wagner D. Protocol: chromatin immunoprecipitation from Arabidopsis tissues. The Arabidopsis Book. 2014:e170.

43. Nagalingam K, Lorenc MT, Manoli S, Cameron SL, Clarke AR, Dudley KJ. Chromatin immunoprecipitation (ChIP) method for non-model fruit flies (Diptera: Tephritidae) and evidence of histone modifications. PloS One. 2018;13(3):e0194420.

44. Gendrel A-V, Lippman Z, Martienssen R, Colot V. Profiling histone modification patterns in plants using genomic tiling microarrays. Nat Methods. 2005;2(3):213.

45. Nagaki K, Talbert PB, Zhong CX, Dawe RK, Henikoff S, Jiang J. Chromatin immunoprecipitation reveals that the 180-bp satellite repeat is the key functional DNA element of Arabidopsis thaliana centromeres. Genetics. 2003;163(3):1221-5.

46. Ricardi MM, González RM, lusem ND. Protocol: fine-tuning of a chromatin immunoprecipitation (ChIP) protocol in tomato. Plant Methods. 2010;6(1):11.

47. Vimont N, Quah FX, Guillaume-Schöpfer D, Roudier F, Dirlewanger E, Wigge PA, et al. ChIP-seq and RNA-seq for complex and low-abundance tree buds reveal chromatin and expression co-dynamics during sweet cherry bud dormancy. bioRxiv. 2019;16(09):334474.

48. Kowar T, Zakrzewski F, Macas J, Kobližková A, Viehoever P, Weisshaar B, et al. Repeat Composition of CenH3-chromatin and H3K9me2-marked heterochromatin in Sugar Beet (Beta vulgaris). BMC Plant Biol. 2016;16(1):120.

49. Sikorskaite S, Rajamäki M-L, Baniulis D, Stanys V, Valkonen JP. Protocol: optimised methodology for isolation of nuclei from leaves of species in the Solanaceae and Rosaceae families. Plant Methods. 2013;9(1):31.

50. Naim F, Nakasugi K, Crowhurst RN, Hilario E, Zwart AB, Hellens RP, et al. Advanced engineering of lipid metabolism in Nicotiana benthamiana using a draft genome and the V2 viral silencingsuppressor protein. PLoS One. 2012;7(12):e52717.

51. Willing E-M, Rawat V, Mandáková T, Maumus F, James GV, Nordström KJ, et al. Genome expansion of Arabis alpina linked with retrotransposition and reduced symmetric DNA methylation. Nature Plants. 2015;1(2):14023.

52. FastQC: a quality control tool for high throughput sequence data Andrews S. FastQC: a quality control tool for high throughput sequence data. 2010. Available online at: http://www.bioinformatics.babraham.ac.uk/projects/fastqc/.

53. Bolger AM, Lohse M, Usadel B. Trimmomatic: a flexible trimmer for Illumina sequence data. Bioinformatics. 2014;30(15):2114-20.

54. Langmead B, Salzberg SL. Fast gapped-read alignment with Bowtie 2. Nat Methods. 2012;9:357-9. 
55. Ramírez F, Ryan DP, Grüning B, Bhardwaj V, Kilpert F, Richter AS, et al. deepTools2: a next generation web server for deep-sequencing data analysis. Nucleic Acids Res. 2016;44(W1):W160-W5.

56. Robinson JT, Thorvaldsdóttir H, Winckler W, Guttman M, Lander ES, Getz G, et al. Integrative genomics viewer. Nat Biotechnol. 2011;29(1):24-6.

57. Akhtar S, Briddon RW, Mansoor S. Reactions of Nicotiana species to inoculation with monopartite and bipartite begomoviruses. Virol J. 2011;8(1):475.

58. Arntzen C. Plant-made pharmaceuticals: from 'edible vaccines' to Ebola therapeutics. Plant Biotechnol J. 2015;13(8):1013.

59. Bandyopadhyay A, Kopperud K, Anderson G, Martin K, Goodin M. An integrated protein localization and interaction map for Potato yellow dwarf virus, type species of the genus Nucleorhabdovirus. Virology. 2010;402(1):61-71.

60. Chan HT, Daniell H. Plant-made oral vaccines against human infectious diseases-are we there yet? Plant Biotechnol J. 2015;13(8):1056-70.

61. Das PM, Ramachandran K, vanWert J, Singal R. Chromatin immunoprecipitation assay. Biotechniques. 2004;37(6):961-9.

62. Nowak DE, Tian B, Brasier AR. Two-step cross-linking method for identification of NF-kappaB gene network by chromatin immunoprecipitation. Biotechniques. 2005;39(5):715.

63. Hoffman EA, Frey BL, Smith LM, Auble DT. Formaldehyde crosslinking: a tool for the study of chromatin complexes. J Biol Chem. 2015;290(44):26404-11.

64. Thavarajah R, Mudimbaimannar VK, Elizabeth J, Rao UK, Ranganathan K. Chemical and physical basics of routine formaldehyde fixation. Journal of oral maxillofacial pathology: JOMFP. 2012;16(3):400.

65. Kaufmann K, Muino JM, Østerås M, Farinelli L, Krajewski P, Angenent GC. Chromatin immunoprecipitation (ChIP) of plant transcription factors followed by sequencing (ChIP-SEQ) or hybridization to whole genome arrays (ChIP-CHIP). Nat Protoc. 2010;5(3):457.

66. Adachi H, Nakano T, Miyagawa N, Ishihama N, Yoshioka M, Katou Y, et al. WRKY transcription factors phosphorylated by MAPK regulate a plant immune NADPH oxidase in Nicotiana benthamiana. Plant Cell. 2015;27(9):2645-63.

67. Cortijo S, Charoensawan V, Roudier F, Wigge PA. Chromatin immunoprecipitation sequencing (ChIPSeq) for transcription factors and chromatin factors in Arabidopsis thaliana roots: From material collection to data analysis. Root Development: Springer; 2018. pp. 231-48.

68. Ghavi-Helm Y, Zhao B, Furlong EE. Chromatin immunoprecipitation for analysing transcription factor binding and histone modifications in. In: Drosophila. Drosophila: Springer; 2016. pp. 263-77.

\section{Figures}




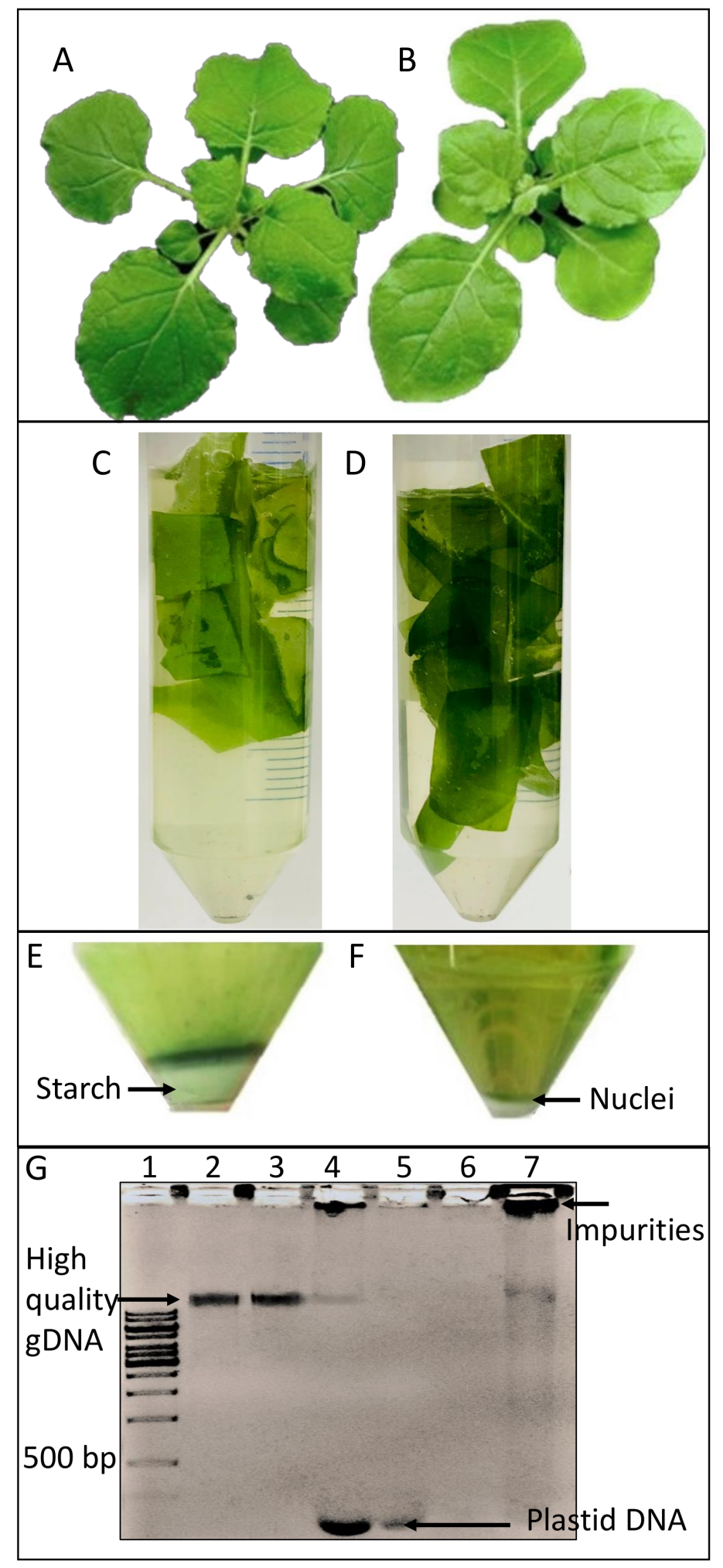

\section{Figure 1}

Images of N.benthamiana leaf samples used for crosslinking and nuclei extraction. A representative five weeks old N.benthamiana plant of Lab (A) and Qld (B) ecotypes. Leaf samples floating on the surface of formaldehyde solution before (C) and after (D) vacuum infiltration appearing translucent, water-soaked and sunken at the bottom of the tube. (E) Chromatin extraction using previously published protocols results in large amounts of starch co-precipitating with DNA and (F) significant reduction in starch with 
nuclei preparation optimised for mature N.benthamiana leaves. (G) Comparison of quality and quantity of chromatin extracted with modified and conventional methods, Lane 1: GeneRuler ${ }^{\mathrm{TM}} 1 \mathrm{~kb}$ DNA Ladder (Thermo Fisher Scientific) Lanes 2 and 3 contain Lab and Qld genomic DNA (gDNA) extracted using modified method, respectively. Lanes 4 and 5 contain Lab gDNA and lanes 6 and 7 contain QId gDNA extracted using conventional method.

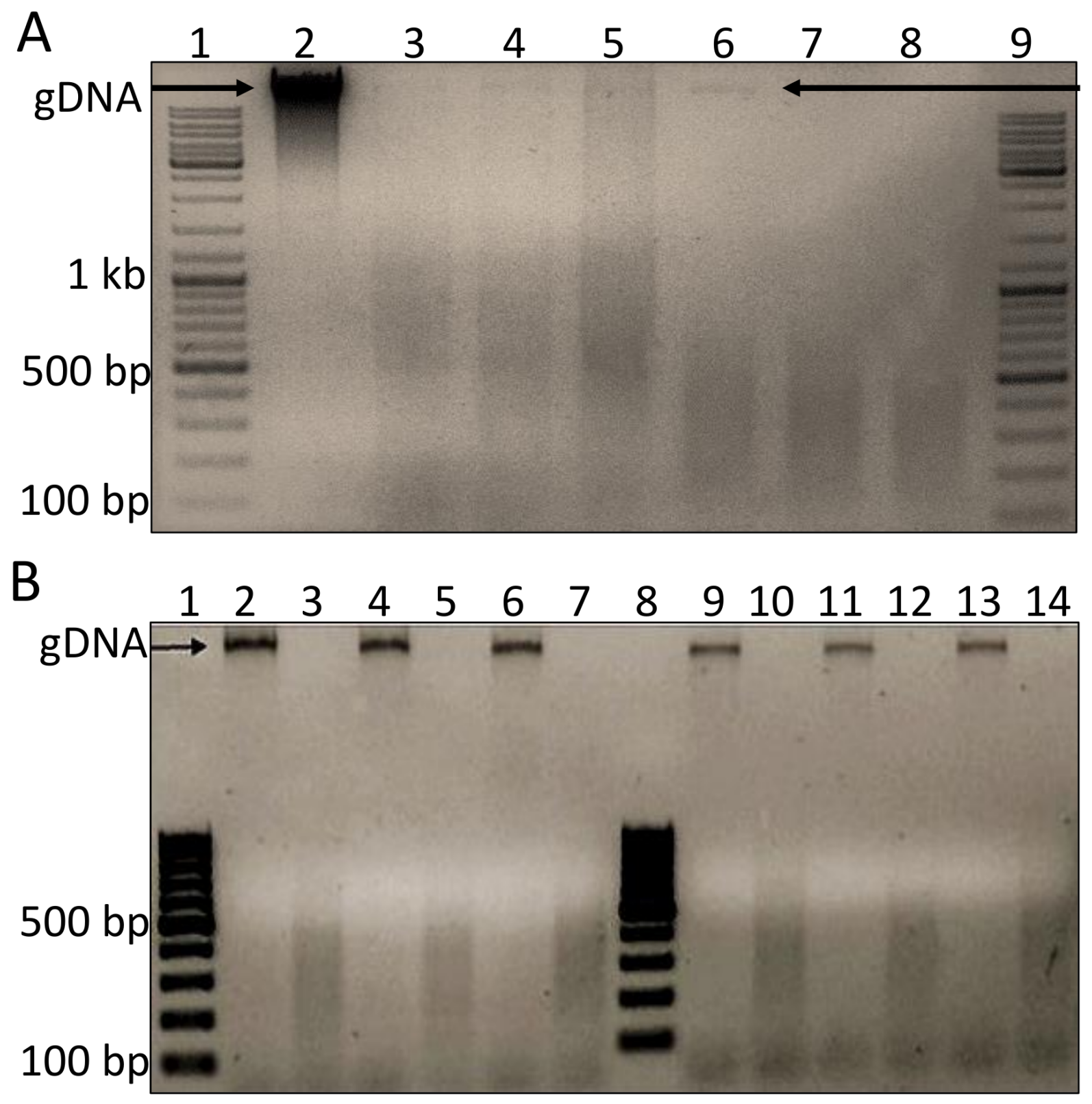

\section{Figure 2}

Comparison of DNA shearing efficiency with conventional and methods modified in this study. (A) Determination of optimum number of sonication cycles with Bioruptor ${ }^{\circledR}$ sonicator and comparison of shearing efficiency with Covaris ultrasonicator. Lanes 1 and 9 include GeneRuler ${ }^{\mathrm{TM}} 100$ bp DNA Ladder (Thermo Fisher Scientific) Lane 2: unsheared genomic DNA, Lanes 3-7 include DNA sheared using Bioruptor sonicator with 14, 16, 18, 20 and 22 cycles, respectively. Lane 8 contains DNA sheared with Covaris ultrasonicator. (B) Three biological replicates of Lab and QId DNA sheared with Covaris 
ultrasonicator. Lanes 1 and 8 contain GeneRuler 100 bp DNA Ladder (Thermo Fisher Scientific). Lanes 2, 4, and 6 contain unsheared and lanes 3, 5, and 7 contain sheared Lab DNA. Lanes 9, 11 and 13 contain unsheared and lanes 10, 12, and 14 contain sheared QId DNA.

\section{Biological replicate 1}
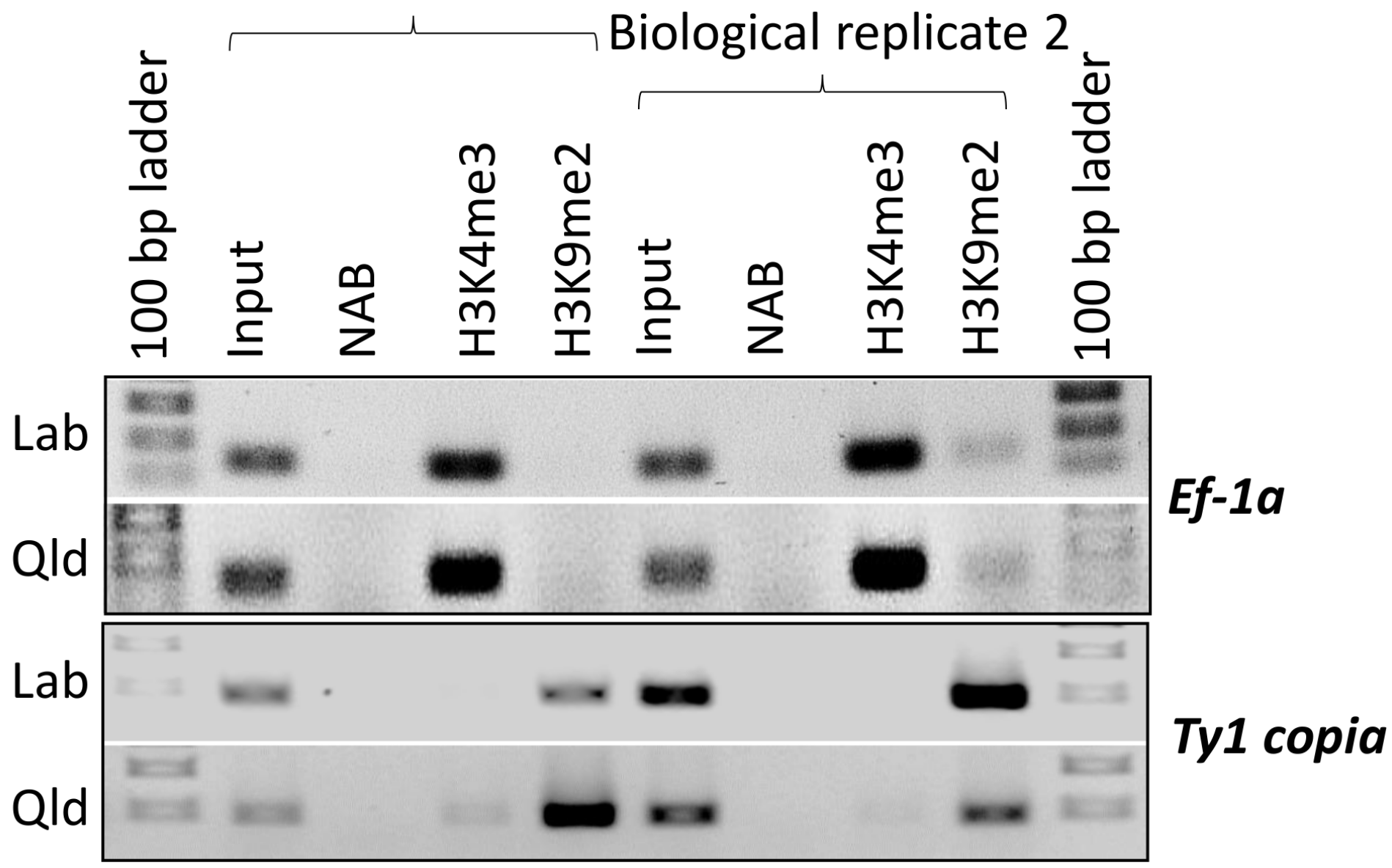

Figure 3

PCR analysis of regions enriched with $\mathrm{H} 3 \mathrm{~K} 4 \mathrm{me} 3$ and $\mathrm{H} 3 \mathrm{~K} 9 \mathrm{me} 2$ for two biological replicates. Primer pairs used for amplification of 200 bp region of EF-1a and Ty1-copia in H3K4me3 and H3K9me2 ChIPs. Input: DNA extracted from the nuclei before the immunoprecipitation step. NAB: No antibody control. 

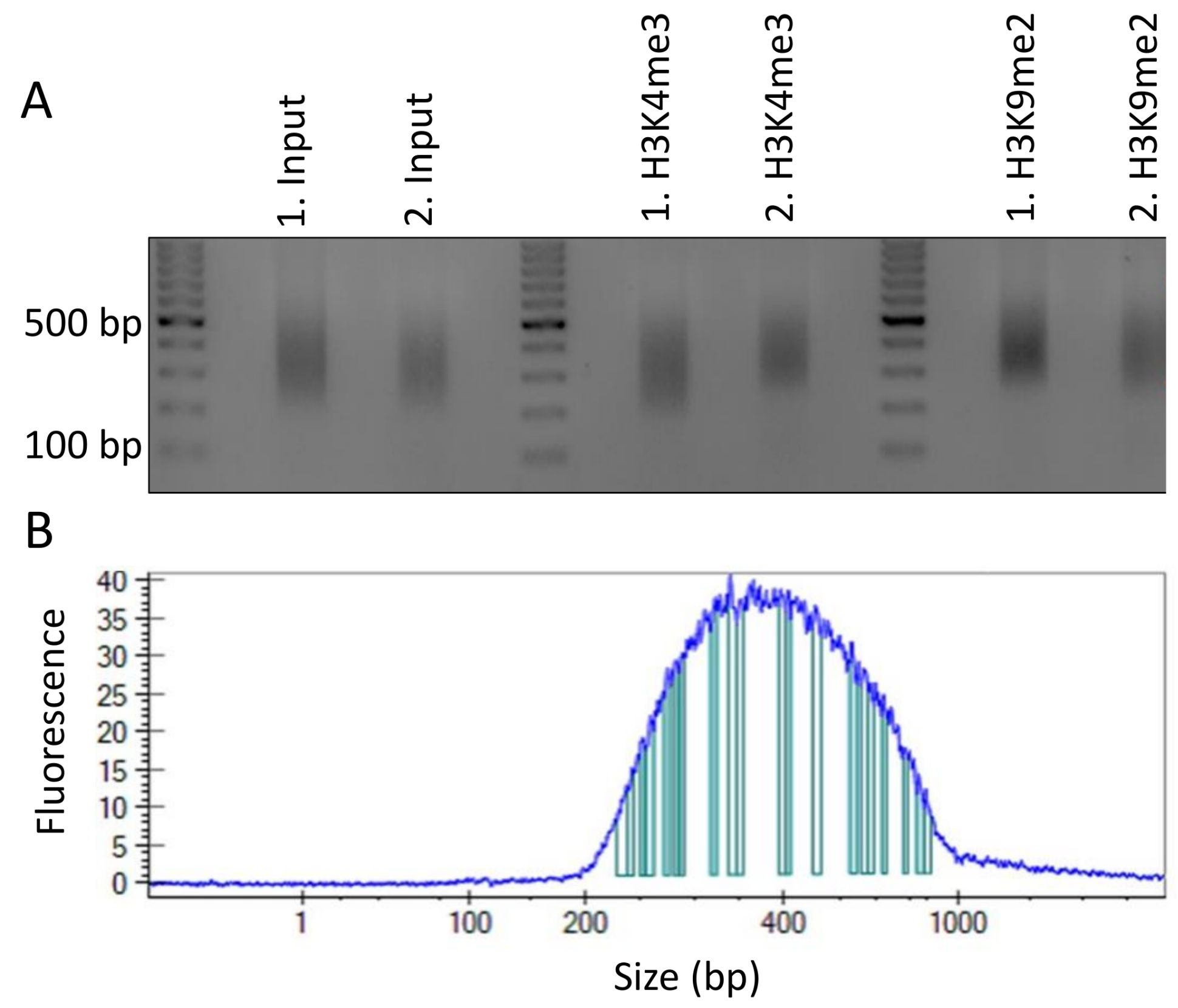

Figure 4

Quality checks of ChIP libraries prepared for next generation sequencing. (A) Standard 1.5\% agarose electropherogram of ChIP libraries (B) A Bioanalyzer chromatogram showing the size distribution of a representative ChIP library. 


\section{Auxin response factor 9}

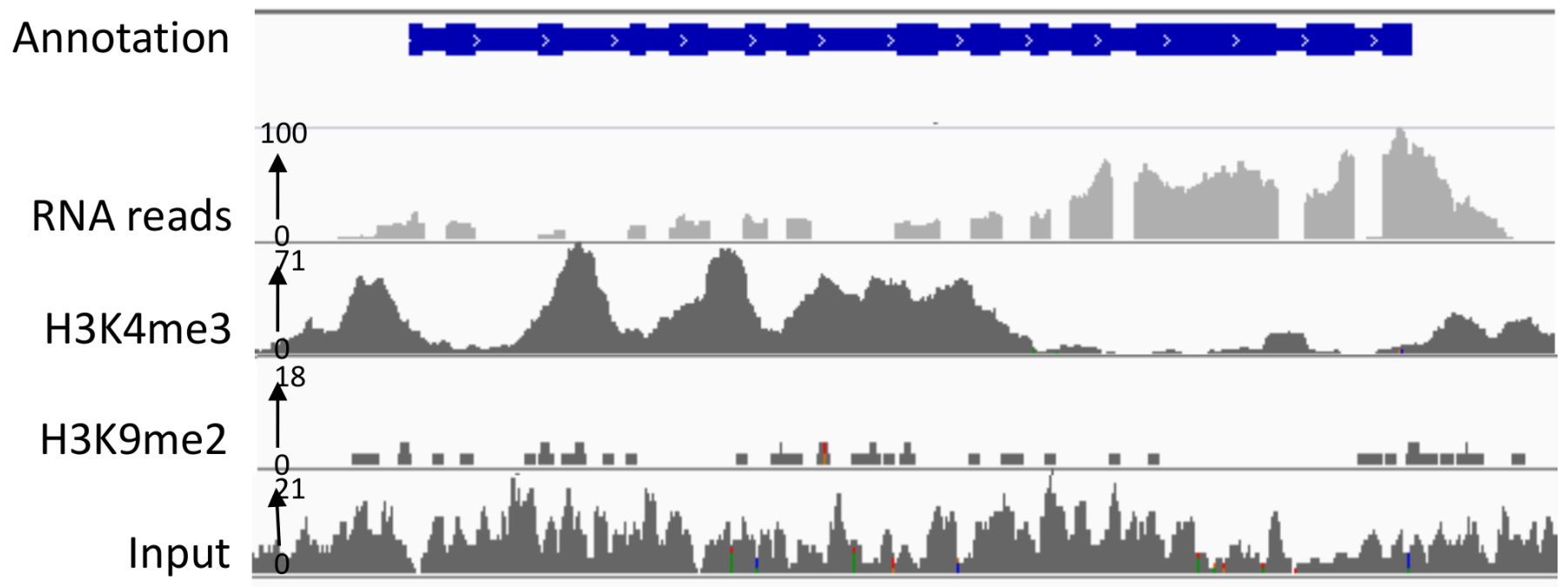

B

PIF-like transposase

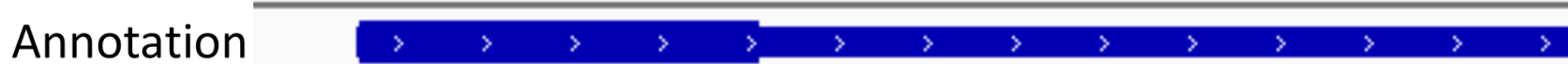

PIF-like transposase

RNA reads $\frac{T_{0}^{10}}{48}$

H3K9me2 $\left.\right|_{0} ^{17}$

Figure 5

IGV view of H3K4me3 and H3K9me2 tracks aligned to N.benthamiana genome scaffolds for two representative genes. The files used for visualisation were generated by bamCompare tools. The tool normalises and compares two BAM files (Input and ChIP) to obtain the log2ratio or difference between them. An overlay of RNA reads obtained from equivalent aged N.benthamiana leaves is also provided. (A) ChIP-seq tracks displaying the fold enrichment and distribution of H3K4me3 over a transcriptionally 
active gene, Auxin response factor 9, in N.benthamiana genome. (B) ChIP-seq tracks displaying the fold enrichment and distribution of $\mathrm{H} 3 \mathrm{~K} 9 \mathrm{me} 2$ over a transcriptionally repressed gene, PIF-like transposase, in N.benthamiana genome.

CONVENTIONAL

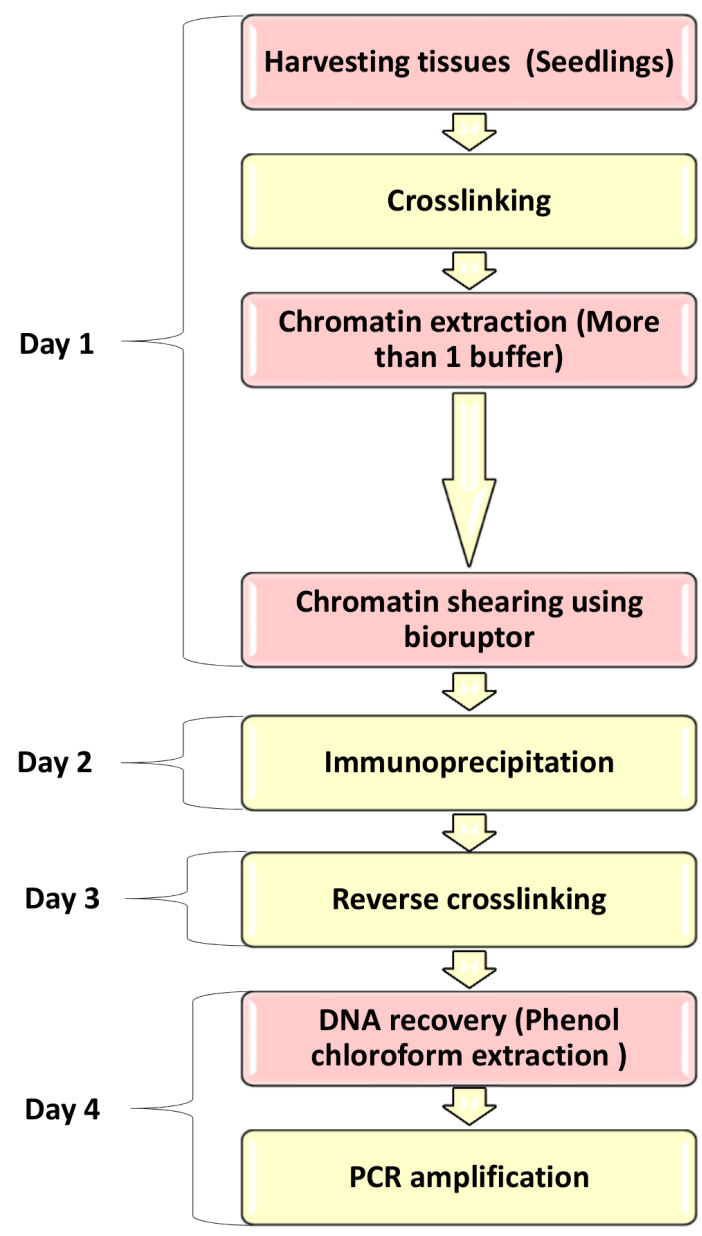

MODIFIED

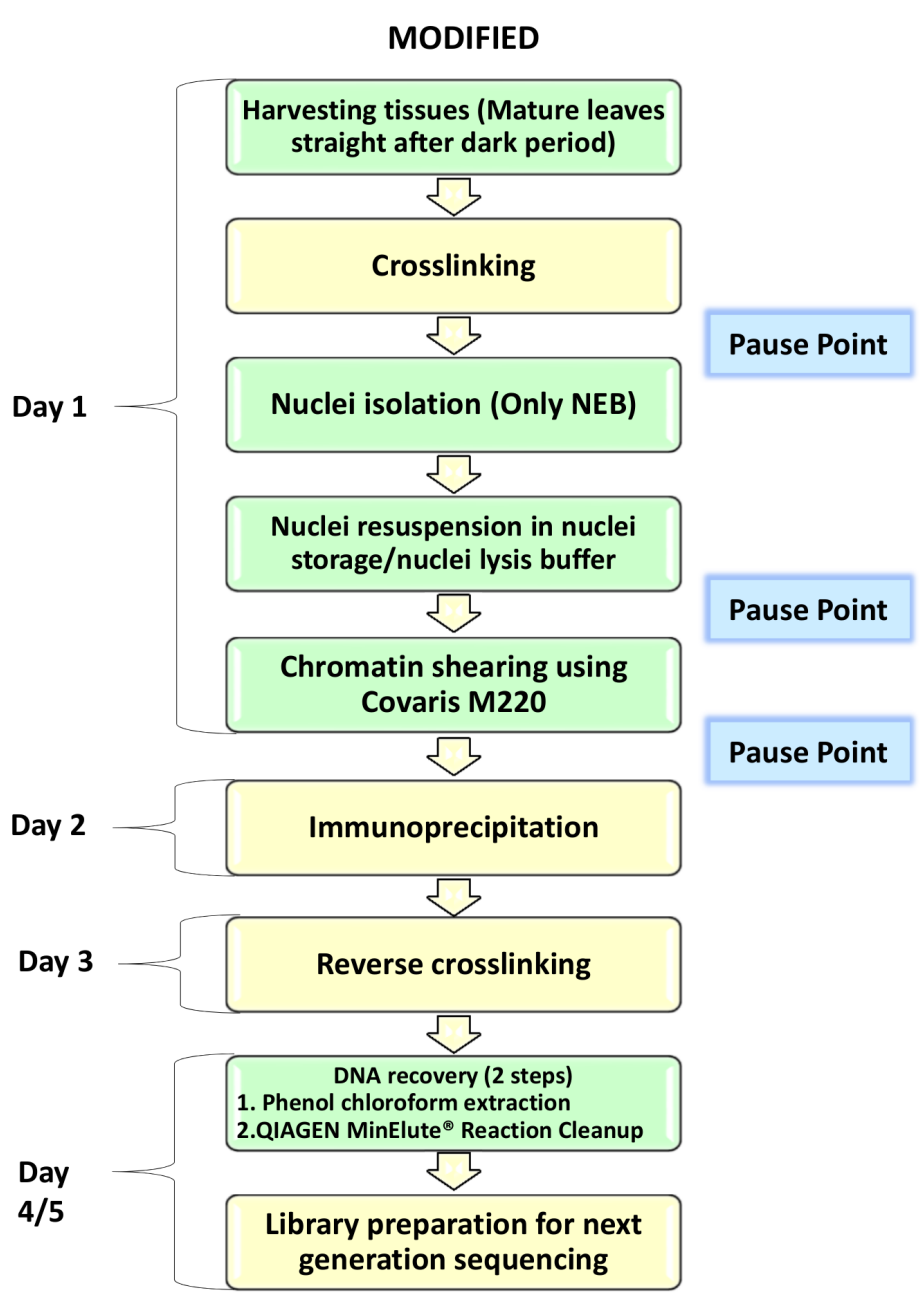

Figure 6

Pause Point

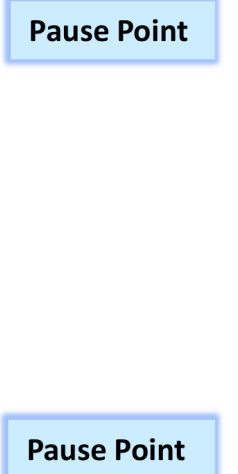

Comparison of conventional ChIP protocol with the protocol optimised for N.benthamiana in this study. Modified steps are highlighted in green and corresponding steps in the conventional protocol are highlighted in red. 